\title{
The Effect of Parenting Behavior on the Obsessive-Compulsive Symptom of College Students: The Mediating Role of Perfectionism
}

\author{
I-Jun Chen*, Mengbi Hu, Hailun Zhang, Zeyao Guo \\ School of Education, Soochow University, Suzhou, China \\ Email: ^herbchen66@163.com
}

How to cite this paper: Chen, I-J., Hu, M. B., Zhang, H. L., \& Guo, Z. Y. (2018). The Effect of Parenting Behavior on the Obsessive-Compulsive Symptom of College Students: The Mediating Role of Perfectionism. Creative Education, 9, 758-778. https://doi.org/10.4236/ce.2018.95057

Received: March 12, 2018

Accepted: April 21, 2018

Published: April 24, 2018

Copyright (c) 2018 by authors and Scientific Research Publishing Inc. This work is licensed under the Creative Commons Attribution International License (CC BY 4.0).

http://creativecommons.org/licenses/by/4.0/

\begin{abstract}
We used a random sample survey of 250 college students in Suzhou district in China to explore the relationships among parenting behavior, perfectionism and obsessive-compulsive symptom, as well as to construct a structural equation model. The results showed that college students' understanding of parenting behavior is above average, they have strong perfectionism and obsessive-compulsive symptoms. College students' obsessive-compulsive symptoms were affected by demographic variables, with gender and grade having significant interaction; parenting behavior causes college students' obsessive-compulsive symptoms, and perfectionism played a mediating role. Understanding the mechanism of parenting behavior and perfectionism on college students' obsessive-compulsive symptoms can provide references to the mental health counseling for college students.
\end{abstract}

\section{Keywords}

Parenting Behavior, Obsessive-Compulsive Symptom, Perfectionism, Mediating Role

\section{Introduction}

With society changing rapidly and fierce competition increasing, the individual differences in mental quality affect the individual's ability to adapt to society, cope with the pressure and develop their potential. As the base for cultivating talents, colleges and universities bear great social responsibility as it is an urgent and essential task to cultivate high quality talents with high social adaptability (Gong \& Lv, 2012). In this case, the individual differences of college students' mental problems have become the focus of attention among families, schools and society. It is found that $20 \%-30 \%$ of college students to have the tendency 
to experience mental problems, $10 \%$ of college students have more serious mental problems, and $1 \%$ of college students have serious mental disorders in China (Yang et al., 2009). Specific groups of college students, such as freshmen, students from low-income families, and graduate students, have more significant mental health problems. The obsessive-compulsive symptom is in first place among the high incidence of mental problems, so it is the prominent problem which affects the college students' mental health (Huz et al., 2016). The obsessive-compulsive symptoms include obsessive thoughts, impulsion, intentions and behavior problems, and continuous invasive experience (Sica et al., 2013), including many dimensions: ordering, checking, aggressive, sexual, obsessing, counting, hoarding, cleaning, etc. In China, among those suffering from obsessive-compulsive disorder, $82 \%$ of them have a high school degree or above, and the average onset age is 22.9 years old. In other words, $69 \%$ of them have shown symptoms before reaching the age of 25 , which is the college period (Zhang, 1991). College students with obsessive tendency tend to express interpersonal discomfort, experience pain in trying to control the symptoms but cannot do so, face more difficulties in learning and in socialization (Mrdjenovich \& Bischof, 2003). If these college students' obsessive-compulsive symptoms cannot be eliminated or alleviated, they may develop deviated mental health and personality. Meanwhile, it will affect the implementation of the national comprehensive quality education and the cultivation of creative talents. As a result, college students' obsessive-compulsive symptoms should be of concern to families, colleges and society.

In family education, parenting behavior is an important factor that influences children's mental health and personality formation, and it can effectively predict the problems of children's obsession, anxiety and depressive emotions (Alonso et al., 2004). Generally, the parenting behavior includes 6 factors: emotional communication, intervention and control, democratic support, excessive protection, denial and dissatisfaction, neglect and indifference. In the studies on obsessive-compulsive patients, it is found that their symptoms are related to their high anxiety state, poor parent-child relationship and their own lack of perceived control towards the external world (Hurlock, 1978). Parents' over expression of refusal and denial, excessive control and protection can significantly affect the generation of children's obsessive-compulsive symptoms (Aycicegi et al., 2002), and the patients' parents lack emotional warmth, understanding, trust and encouragement compared to general parents. Moreover, they exert more punishment, refusal and denial (Ehiobuche, 1988). This study shows that obsessive-compulsive patients' fathers express excessive refusal, while their mothers express excessive interference and protection (Chen et al., 2010). Obviously, inappropriate parenting behavior is related to the children's obsessive-compulsive symptoms.

\subsection{Perfectionism}

Perfectionism is a stable personality trait which refers to the individual who 
strives to complete tasks perfectly, along with very strict self-assessment and evaluation; many factors are included: concern over mistake, doubting of actions, personal standards, organization, parental expectations, parental blame, etc. (Frost \& Marten, 1990). Perfectionism and mental health are negatively correlated (Schweitzer \& Hamilton, 2002). Perfectionism is considered as one of the obsessive-compulsive disorders' six core cognitive beliefs (Obsessive Compulsive Cognition Working Group, 1997); obsessive-compulsive disorder patients' pursuits are exceedingly perfect compared to those of normal people (Melli et al., 2015). In 1980, the American Psychiatric Association developed the Diagnostic and Statistical Manual of Mental Disorders (DSM-III) added perfectionism as one of the diagnostic criteria for the obsessive-compulsive personality disorder. Obviously, perfectionism has become an important predictor of obsessive-compulsive symptoms (Martinelli et al., 2014).

Previous studies have suggested that perfectionism is a result of interaction between children and parents (e.g., Zhang \& Chen, 2013; Flett \& Hewitt, 2002; Barrett et al., 1996; Kaner et al., 1993; Bandura \& Kupers, 1964). An individual's early life experience in the family, especially regarding parents' criticism and expectations are crucial to the formation of perfectionism (Hollender, 1978). The studies by Fang et al. found that college students' perfectionism is related to their parents' rearing patterns (Fang et al., 2007). On the perceptual level, children's perfectionism is influenced by their parents' perfectionism (Aycicegi et al., 2002). Zhang and Chen (2013)'s study found that passive parenting styles negatively predict adaptive perfectionism, and positively predict non-adaptive perfectionism (Zhang \& Chen, 2013). Parenting behavior clearly has an important influence on the formation of perfectionism.

\subsection{This Study}

Previous researches did not have a concerted scale for perfectionism measurement of Chinese college students; research on parenting behavior's effect on their children's obsessive-compulsive disorder did not consider the mediating effect of personality. However, children's personality must be an inevitable part in the process of parenting's effect on their behavior. For further studies, it is necessary to clarify the relationships among these three factors to understand the mechanism of parenting behavior and perfectionism on college students' obsessive-compulsive symptoms, and provide reference for the college students' mental health education in universities.

Therefore, this study revises the existing questionnaires to investigate the relationships among parenting behavior, perfectionism and obsessive-compulsive symptoms concerning college students. Hence, this paper hypothesizes that perfectionism plays an important mediating role between parenting behavior and college students' obsessive-compulsive symptoms. The specific research hypothesis is as follows:

1) College students' obsessive-compulsive symptoms were affected by demo- 
graphic variables, and different population background variables have interactive effects.

2) Parenting behavior directly affect college students' compulsion, and perfectionism played a mediating role.

\section{Method}

\subsection{Participants}

In this study, a random sampling method was used to extract 250 students as participants from public college students in the Suzhou area $\left(M_{\text {age }}+S D_{\text {age }}=\right.$ $22.50 \pm 1.94)$ to fill in questionnaires; 223 questionnaires were valid (89.2\%). A power analysis revealed that this sample size was sufficient $(1-\beta=0.86)$, yet not so large as to capitalize on small effects that have little practical significance (Kirk, 1996). The information of the participants is shown in Table 1.

\subsection{Procedure}

This study randomly selected 250 undergraduates from five universities in Suzhou as participants. After obtaining the informed consent of the participants, measures were completed in the prescribed classroom at a prescribed time. All the data were collected from five measures and collected about 50 copies each time. The tests were conducted by the same researcher. Before each test, the researcher first explained the significance of this survey in the instruction and emphasized that the survey was anonymous and there was no right or wrong answer, and the participants were asked to answer according to their real situations. Then, the investigators distributed a scale and two questionnaires to the participants in sequence in the classroom (see Appendix). The time required for the participants to complete the questionnaires was about 45 minutes. Participants volunteered to participate in the experiment and were not compensated for their participation.

Table 1. The participants information.

\begin{tabular}{cccc}
\hline Variable & Type & Number & Frequency (\%) \\
\hline \multirow{4}{*}{ Male } & Female & 125 & 56.1 \\
& Grade one & 98 & 43.9 \\
Gender & Grade two & 49 & 22.0 \\
Grade & Grade three & 47 & 21.1 \\
Major & Grade four & 75 & 33.6 \\
& Business management & 52 & 23.3 \\
& Humanities and social sciences & 50 & 33.2 \\
& Science and engineering & 44 & 22.4 \\
& Medical science & 41 & 19.7 \\
& Arts & 14 & 18.4 \\
& & & 6.3 \\
\hline
\end{tabular}




\subsection{Measures}

Parenting Behavior Scale for College Students (PBSCS). This self-compiled scale was based on the research of Barrett, Shortt, \& Healy (2002), Storch, Geffken, Merlo, Jacob, Murphy, Goodman et al. (2007), and integrated the early in-depth interview. The in-depth interviews were conducted with 50 students who were randomly selected from four universities in the southern Jiangsu area. We then used content analysis based on the grounded theory to encode the electronic text three times; the final core categories were derived to establish four dimensions of parenting behavior, with which to form the PBSCS preliminary questionnaire with 50 items. The pretest found that the discrimination of 50 items were extremely significant related to the total score $(p<0.001)$, the coefficient of KMO was 0.90, and Bartlett's test of sphere value was 2072.27, $p<0.001$, indicating that the questionnaire was suitable for factor analysis. According to the maximum variance method, the principal components analysis method was used to undertake the rotation to determine the final component matrix. After several rounds of analyses, we kept 30 items which could explain $63.26 \%$ of total variation. It contains six dimensions: emotional communication, intervention and control, democratic support, excessive protection, denial and dissatisfaction, neglect and indifference. Then the formal PBSCS was formed. Items were scored on a 5-point Likert scale ranging from 1 (strongly disagree) to 5 (strongly agree). The higher the score, the higher the frequency of parents having adopted this parenting behavior. The internal consistency coefficient (Cronbach $\alpha$ coefficient) of the six factors was between $0.41-0.85$, and the split half reliability was between $0.36-0.87$. The internal consistency coefficient of the scale was 0.54 , and the split half reliability was 0.46 . Confirmatory factor analysis showed that all the projects' factor loading were above.40. The model fit indices are as follows: $\chi^{2}=$ 216.43, $d f=233, \chi^{2} / d f=0.93, G F I=0.92, C F I=1.00, N F I=0.90$ and $R M S E A=$ 0.003 , reaching the ideal standard. Therefore, this table has ideal construct validity.

Perfectionism Questionnaire for College Students (PQCS). We made this questionnaire referencing Frost et al. (1990) and Xie (2005)'s researches. Exploratory factor analysis found that 35 items' discrimination index and total score's correlation reached an extremely significant level $(p<0.001)$. The KMO coefficient was .78 and the Bartlett sphere test value was $1466.28, p<0.001$, which indicated that the questionnaire was suitable for factor analysis. According to the maximum variance method, we used the principal components analysis method to undergo the rotation to find the final component matrix. After several rounds of analyses, we kept 28 items which could explain $49.52 \%$ of total variation, including seven factors: high standard, self-concern, self-reflection, organization, fear of mistakes, self-doubt and parental expectation. Items were scored on a 5 -point Likert scale ranging from 1 (strongly disagree) to 5 (strongly agree). The higher the score, the higher the tendency of perfectionism. The internal consistency coefficient (Cronbach $\alpha$ coefficient) of the seven factors was between 0.46 - 
0.83 , and the split half reliability was between $0.53-0.74$. The internal consistency coefficient of the entire questionnaire was 0.79 , and the split half reliability was 0.67. Confirmatory factor analysis showed that the factor loading of the whole project was above.40. The model fit indices are as follows: $\chi^{2}=215.28, d f$ $=228, \chi^{2} / d f=0.94, G F I=0.92, C F I=1.00, N F I=0.90$ and $R M S E A=0.002$, expressing the questionnaire's good reliability and validity.

Obsessive-Compulsive Disorders Questionnaire for College Students (OCDQCS). We used OCDQCS compiled by Wu (2006), which included 25 items and eight factors: ordering, checking, aggressive, sexual, obsessing, counting, hoarding and cleaning. The scoring was based on a 5-point scale; the higher the score, the more obvious the obsessive-compulsive symptoms. Reliability analysis of this study found that the internal consistency coefficient was 0.88 , the internal consistency coefficient of the eight constructs was between $0.52-0.73$, which could explain $61.63 \%$ of the total variation. In addition, this questionnaire proved to have good construct and convergent validity ( $\mathrm{Wu}, 2006)$.

Statistical analyses. SPSS17.0 was used to describe the data statistics, analysis of variance and correlation analysis, while AMOS17.0 was used to conduct confirmatory factor analysis and construct the structural equation model. Missing data were dealt with by pairwise deletion, which was judged reasonable given that pairwise missing data was below $5 \%$ for all pairs of observed variables. Harman single factor method was used to test the deviation of the common method. After the factor analysis, we obtained 21 factors with characteristic values greater than one; the first factor explained the variance of $18 \%$, which was much lower than the critical value of $40 \%$. Therefore, there is no serious common method bias in this study.

\section{Results}

\subsection{A Status Analysis of Parenting Behavior, Perfectionism and Obsessive-Compulsive Symptoms among College Students}

Table 2 shows that among the parenting behaviors experienced by college students, emotional communication scored the highest, while neglect and indifferent scored the lowest. The college students' perfectionism was in the middle to upper level; organization was the highest, and fear of mistakes was the lowest. College students showed obsessive-compulsive symptoms but not obviously. The hoarding scored the highest, while aggressive scored the lowest.

\subsection{Analysis of College Students' Obsessive-Compulsive Symptoms in Different Demographic Variables}

\subsubsection{Analysis of the Differences among the College Students' Obsessive-Compulsive Symptoms Regarding Different Demographic Factors}

There were significant differences in the obsessive-compulsive symptoms among college students according to gender. The male students' scores were significantly higher than those of the females. In each dimension, male students scored 
Table 2. Descriptive Statistics of College Students' Parenting Behavior, Obsessive-compulsive Symptoms and Perfectionism $(\mathrm{N}=223)$.

\begin{tabular}{ccccccccc}
\hline Item & $M$ & $S D$ & Item & $M$ & $S D$ & Item & $M$ & $S D$ \\
\hline $\begin{array}{c}\text { Parenting } \\
\text { Behavior }\end{array}$ & 2.91 & 0.2 & $\begin{array}{c}\text { Obsessive- } \\
\text { compulsive } \\
\text { Symptom }\end{array}$ & 2.31 & 0.51 & Perfectionism & 3.39 & 0.38 \\
$\begin{array}{c}\text { Emotional } \\
\text { Communication } \\
\text { Intervention } \\
\text { and Control }\end{array}$ & 4.12 & 0.68 & Ordering & 2.9 & 0.78 & $\begin{array}{c}\text { High } \\
\text { Standard }\end{array}$ & 3.67 & 0.82 \\
$\begin{array}{c}\text { Democratic } \\
\text { Support }\end{array}$ & 3.98 & 0.66 & Aggressive & 1.42 & 0.68 & Self-reflection & 3.5 & 0.54 \\
$\begin{array}{c}\text { Excessive } \\
\text { Protection }\end{array}$ & 2.72 & 0.56 & Sexual & 2.22 & 0.76 & Organization & 3.8 & 0.55 \\
$\begin{array}{c}\text { Denial and } \\
\text { Dissatisfaction } \\
\text { Neglect and } \\
\text { Indifferent }\end{array}$ & 1.89 & 0.6 & Obsessing & 2.51 & 0.65 & $\begin{array}{c}\text { Fear of } \\
\text { mistakes }\end{array}$ & 2.57 & 0.62 \\
& 1.64 & 0.64 & Counting & 2.17 & 0.73 & Self-doubt & 3.01 & 0.8 \\
& & & Hoarding & 3.08 & 1 & $\begin{array}{c}\text { Parental } \\
\text { expectation }\end{array}$ & 3.54 & 0.71 \\
\hline
\end{tabular}

significantly higher than female students did in ordering, checking, sexual and obsessing. There were significant differences in the obsessive-compulsive symptoms in different majors. The college students majoring in business management scored significantly higher than those majoring in the humanities and social sciences. Among all the factors, there was a significant difference in ordering, but it was not significant in the post hoc test. However, the score of the business management major was significantly higher than that of the humanities and social sciences in checking. There were no significant differences among all the grades of college students' obsessive-compulsive symptoms (see Table 3).

\subsubsection{Interactive Analysis of College Students with Obsessive-Compulsive Symptoms Concerning Gender and Grade} Based on the studies of obsessive-compulsive symptoms on college students, the degree of college students' obsessive-compulsive symptoms was affected by gender and grade (Bundros et al., 2016). This study thus further analyzed the interactions between gender and grade on the obsessive-compulsive symptoms of college students. As shown in Table 4, the interaction between gender and grade was significant $(F=4.20, p<0.01)$; the main effect of gender was significant $(F=$ $5.67, p<0.05)$.

The interaction between gender and grade was significant. The simple effect analysis was carried out. The results in Table 5 show that the simple effect of gender reached the significant level. Among the freshmen or sophomores, male students exhibited more obvious obsessive-compulsive symptom than female students did $(F=6.08, p<0.05 ; F=10.30, p<0.01)$. At the same time, the simple effect of grade was also significant. Among female college students, the total score of seniors was higher than those of the freshmen, sophomores and juniors. 
Table 3. Variance analysis among the college students' obsessive-compulsive symptoms regarding different demographic factors.

\begin{tabular}{|c|c|c|c|c|c|}
\hline Item & & Gender & Grade & Major & Only child \\
\hline \multirow{3}{*}{$\begin{array}{l}\text { Obsessive-compulsive } \\
\text { Symptom }\end{array}$} & $t$-value/ $F$-value & $2.86^{\star *}$ & 0.37 & $2.97^{\star}$ & 0.91 \\
\hline & Scheffe & $a>b$ & & $c>d$ & \\
\hline & $E S$ & 0.16 & & 0.45 & \\
\hline \multirow{3}{*}{ Ordering } & $t$-value/ $F$-value & $2.16^{\star}$ & 1.25 & $3.47^{\star *}$ & 0.37 \\
\hline & Scheffe & $a>b$ & & () & \\
\hline & $E S$ & 0.20 & & 0.52 & \\
\hline \multirow{3}{*}{ Checking } & $t$-value/ $F$-value & $2.14^{*}$ & 0.19 & $4.01^{* *}$ & 0.83 \\
\hline & Scheffe & $a>b$ & & $c>d$ & \\
\hline & ES & 0.20 & & 0.60 & \\
\hline \multirow{3}{*}{ Aggressive } & $t$-value $/ F$-value & 2.23 & 2.57 & 1.86 & 0.25 \\
\hline & Scheffe & & & & \\
\hline & ES & & & & \\
\hline \multirow{3}{*}{ Sexual } & $t$-value/ $F$-value & $6.41^{* * *}$ & 2.04 & 1.17 & 0.41 \\
\hline & Scheffe & $a>b$ & & & \\
\hline & ES & 0.61 & & & \\
\hline \multirow{3}{*}{ Obsessing } & $t$-value/ $F$-value & $2.81^{\star \star}$ & 1.84 & 2.07 & 0.56 \\
\hline & Scheffe & $a>b$ & & & \\
\hline & ES & 0.27 & & & \\
\hline \multirow{3}{*}{ Counting } & $t$-value/ $F$-value & 1.06 & 2.50 & 1.93 & 0.47 \\
\hline & Scheffe & & & & \\
\hline & $E S$ & & & & \\
\hline \multirow{3}{*}{ Hoarding } & $t$-value/ $F$-value & -0.89 & 2.65 & 2.37 & 0.55 \\
\hline & Scheffe & & & & \\
\hline & $E S$ & & & & \\
\hline \multirow{3}{*}{ Cleaning } & $t$-value/ $F$-value & 0.78 & 0.93 & 0.64 & 0.79 \\
\hline & Scheffe & & & & \\
\hline & $E S$ & & & & \\
\hline
\end{tabular}

Notes. $\mathrm{a}=$ Male; $\mathrm{b}=$ Female; $\mathrm{c}=$ Business Management; $\mathrm{d}=$ Social Sciences. $\bigcirc$ Scheffe test showed that there was no significant difference between any of the two groups. ${ }^{*} p<0.05,{ }^{* *} p<0.01,{ }^{* *} p<0.001$.

Table 4. Variance analysis of the interaction between gender and grade of college students with obsessive-compulsive symptoms.

\begin{tabular}{cccccc}
\hline Source of Variation & $\boldsymbol{S S}$ & $\boldsymbol{d f}$ & $\boldsymbol{M S}$ & $\boldsymbol{F}$ & $\boldsymbol{E S}$ \\
\hline Gender & 1.39 & 1 & 1.39 & $5.67^{*}$ & 0.54 \\
Grade & 0.98 & 3 & 0.33 & 1.34 & \\
Gender $\times$ Grade & 3.09 & 3 & 1.03 & $4.20^{* *}$ & 0.69 \\
Deviation & 52.70 & 215 & 0.25 & & \\
\hline
\end{tabular}

${ }^{*} p<0.05,{ }^{* *} p<0.01$. 
Table 5. Simple Main Effect of College Students' Obsessive-compulsive Symptoms between Gender and Grade.

\begin{tabular}{|c|c|c|c|c|c|}
\hline Source of variation & $S S$ & $d f$ & $M S$ & $F$ & Scheffe \\
\hline \multicolumn{6}{|c|}{ Grade } \\
\hline Freshman & 1.52 & 1 & 1.52 & $6.08^{*}$ & male $>$ female \\
\hline Sophomore & 1.63 & 1 & 1.63 & $10.30^{\star *}$ & male $>$ female \\
\hline Junior & 1.03 & 1 & 1.03 & 3.35 & \\
\hline Senior & 0.86 & 1 & 0.86 & 3.76 & \\
\hline \multicolumn{6}{|c|}{ Gender } \\
\hline Male & 0.67 & 3 & 0.22 & 0.74 & \\
\hline Female & 2.58 & 3 & 0.86 & $5.07^{\star *}$ & $\begin{array}{c}\text { senior }>\text { freshman } \\
\text { senior }>\text { sophomore } \\
\text { senior }>\text { junior }\end{array}$ \\
\hline
\end{tabular}

\subsection{Structural Equation Model of the Influence of PB and Perfectionism on College Students' Obsessive-Compulsive Symptoms}

This study conducted correlation analysis on the scores of PBSCS, PQCS and $O C D Q C S$. The results showed that the emotional communication, intervention and control, and denial and dissatisfaction in parenting behaviors were significantly correlated with perfectionism. The correlation coefficient $r$ values ranged from -0.13 to 0.18 ; emotional communication, intervention and control, democratic support, denial and dissatisfaction, neglect and indifference and the obsessive-compulsive symptoms were significantly correlated: $r$ values ranged from 0.31 to 0.42 ; the score of perfectionism scale and the obsessive-compulsive symptom score were significantly correlated: $r$ values was 0.34 , parenting behavior (democratic support, emotional communication, neglect and indifference, denial and dissatisfaction, and intervention and control), perfectionism and obsessive-compulsive symptoms were pairwise correlated significantly, indicating that perfectionism may play a mediating role in parenting behavior and obsessive-compulsive symptoms, making it suitable to establish structural equation model.

Based on the intermediary effect test proposed by Baron \& Kenny (1986), the intermediary effect of perfectionism between the parenting behavior (emotional communication, intervention and control, denial and dissatisfaction, democratic support, and neglect and indifference) and obsessive-compulsive symptoms was analyzed. The parameters were estimated and tested by using the maximum likelihood method of the covariance structure model. The results showed that the effect of democratic support and neglect and indifference on college students' obsessive-compulsive symptoms were not significant; hence, these two factors were removed. The direct effect model fitting degree of parenting behavior (emotional communication, intervention and control, denial and dissatisfaction) 
on obsessive-compulsive symptoms was: $\chi^{2} / d f=1.80, G F I=0.95, C F I=0.96$, $N F I=0.92$ and $R M S E A=0.06$, so the index was good. After adding perfectionism variables, we found that the effect of emotional communication and intervention and control on perfectionism were not significant. In the final model, the model fitting index was: $\chi^{2} / d f=1.93, G F I=0.91, C F I=0.91, I F I=0.92$ and $R M S E A=0.07$, indicating a good fit of the model. Moreover, parents' intervention and control and emotional communication would directly affect college students' obsessive-compulsive symptoms; path coefficients were 0.26 and 0.19 ; denial and dissatisfaction would directly affect the perfectionism, path coefficient was 0.22 ; perfectionism's path coefficient of obsessive-compulsive symptom score was 0.38. All the path coefficients had statistical significance. By increasing perfectionism research variables, we found that the direct predictive effect of denial and dissatisfaction on college students' obsessive-compulsive symptoms dropped from 0.19 to 0.08 , which was not significant, indicating that perfectionism in denial and dissatisfaction behavior and college students' obsessive-compulsive symptoms exhibited complete intermediary effect (Figure 1).

\section{Discussion}

The results of this study showed that college students' cognition of parenting behavior was at the upper level, emotional communication scored the highest, neglect and indifference scored the lowest, suggesting that college students generally realized that their parents pay attention to parent-child emotional communication. In recent years, with the rapid development of education and the spread of media, parents are able to obtain correct parenting knowledge more easily (Schaub, 2010). The increasingly developed communication has objectively increased the opportunity to interact with the children, reducing the emotional barriers. The majority of college students born in the 90s are the only child, leaving their parents to enter universities. Regardless of material and spiritual life, they are highly supported and concerned by their parents; in this case, the score of neglect and indifference was the lowest.

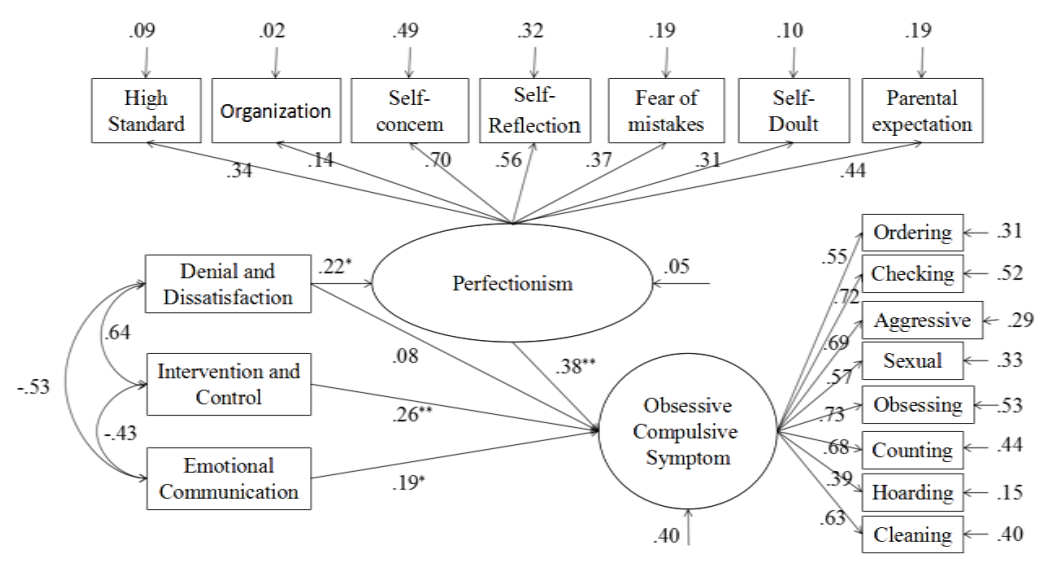

Figure 1. The Relationships among Parenting Behavior, Perfectionism and Obsessive-compulsive Symptom. 
College students' perfectionism was at the upper level; organization scored the highest, while fear of mistakes scored the lowest. The government has attached great importance to education, and society has great expectations regarding college students. However, when students are externally imposed by external criteria, if they cannot meet expectation and lack resilience, they would feel stressed and their perfectionism reinforced (Klibert et al., 2014). Organization refers to individuals always tending to keep things neat, behave normally, or keep the details in life orderly, which reflects the individual's sense of control. After completing the exam-oriented high school education, college students face a variety of choices, so it is inevitable that they might feel confused; the regulated behavior can make up for this sense of confusion, and enhance the sense of security. Another reason is that today's college education encourages students to try out new things and innovate. As students pay more attention to the process of innovation rather than the results, the fear of mistakes would be diminished. College students should develop their self-regulation ability, learn the correct ways to release stress, and regulate their emotions and attitude; at the same time, society and parents also need to proceed from reality, with reasonable expectations, giving their children proper evaluation, avoiding the development of excessive perfectionism tendency. College educators should pay attention to the psychological adjustment of college students, and carry out the activities to relieve stress and improve the psychological status of college students.

This study found that for college students with obsessive-compulsive symptoms, the hoarding scored the highest, and aggressive scored the lowest. Hoarding reflects individuals' uncertainty and psychological insecurity. When college students leave the care of their parents and enter college, they feel more social demands and pressure, they start to collect stuff to bring them a sense of security, which is a special kind of defense mechanism in facing the pressure. The aggressive reflect the impulse of the individual to harm themselves or others. College students are mostly elites, so they can learn to solve their problems through scientific methods and use a fundamental approach to communicate rather than force to solve problems in life; hence, their aggressive level is low. In order to prevent the occurrence of obsessive-compulsive symptoms, class counselors in colleges and universities can teach students how to achieve a reasonable psychological catharsis and adjustment through lectures. Class psychological commissioners can pay close attention to the students; they should promptly report to the class counselors once they identify students who are hoarding, and to persuade them to seek psychological help proactively.

In terms of gender, male college students' scores were significantly higher than female students in the total score of obsessive-compulsive symptoms, mainly in ordering, checking, sexual and obsessive. This suggests that gender characteristic differences exist between male and female students (Chen et al., 2013). Male characteristics emphasize being decisive and independent, with the habit of autonomous decision-making, but easily doubting after the decision; 
female characteristics emphasize cooperation, communication and empathy, and share less responsibility and stress, so general obsessive ideas is lower than the males'. In terms of their major, females prefer to choose social class, with learning content based on human behavior and social care, while males prefer to choose science and engineering majors; being good at calculating and practicing is closely related to ordering and checking, so they behave more obsessively to order/check than females do. Sexual describe individuals subject to the concept of sexual coercion. Influenced by physiological factors, males are more likely than females to experience sexual impulses (Jun, 2007). Coupled with the impact of social stereotypes, males play the active role in gender interaction, while females are passive seekers, so the obsessive thoughts of males are higher than female's. Further interactive analysis on obsessive-compulsive symptoms concerning gender and grade examined the gender differences among students of different grades. In terms of gender, the results showed that male freshmen and sophomores' obsessive-compulsive symptoms were significantly higher than females. This is probably because students in lower grades were still adapting to college life, while female students' adaptation ability was significantly higher than that of the male students (Li et al., 2011); however, students who have better life adaptation ability can successfully solve problems, thereby avoiding the obsessive-compulsive symptoms and behavioral problems. However, regarding gender in obsessive-compulsive symptoms in different grades, it is found that female seniors' obsessive-compulsive disorder was significantly higher than that of the other students in the lower grades. This result is probably because compared with male seniors, female seniors need to face important choices for employment, examinations in applying for graduate school or marriage after graduation; as the pressure becomes stronger, it tends to produce obsessive choice behavior. In today's job market, due to the sensitive avoidance and demands on females' martial age, child-bearing age and gender, the males are more preferred than females; with the female's increased pressure, the obsessive-compulsive symptoms increase accordingly. Therefore, female college students should start to set their own goals reasonably at the beginning of school, preventing the pressure from getting too heavy and causing obsessive-compulsive symptoms upon graduation. Schools should pay more attention to the adaptation problems of students in lower grades, and start fraternities, seminars and other activities to enable the students to quickly adapt to college life. Moreover, counselors should pay attention to the psychological status of female graduates, and give practical guidance and help to their career planning after graduation.

In terms of their major, the obsessive-compulsive symptoms of students in the graduate school of business management was significantly severer compared to students in the humanities and social sciences, especially in the hoarding, which may be related to the organizational climate of the study fields. The emotional and behavior problems of individuals were more likely to generate anxiety in a serious and stressful organizational climate. Business management takes accura- 
cy and efficiency as the standard and the atmosphere is serious, while humanities and social sciences encourage divergent and innovative thinking, the atmosphere is more relaxed, so business management students are more likely to have hoarding behavior, compared to the humanities and social sciences students. Therefore, we suggest that the business management school should carry out rich and colorful extracurricular activities to help students relax and adjust to the pressure of academic life brought by the schoolwork.

In this study, we found that parental emotional communication, intervention and control directly affected the students' obsessive-compulsive symptoms; college students' perfectionism positively predicted their obsessive-compulsive symptoms; and parents' behavior of denial and dissatisfaction has an indirect effect through the perfectionism of college students' obsessive-compulsive symptoms.

Parental emotional communication behavior has a significant negative impact on college students' obsessive-compulsive symptoms, that is, the higher the emotional communication behavior, the lower the obsessive-compulsive symptoms. Previous studies found that emotional warmth and understanding in parenting behavior have a good effect on children's cognitive development, socialization and personality formation, while low emotional communication significantly predicts children's obsessive-compulsive symptoms occurrence when they grow up (Bouchard et al., 1999). Parental support and care bring the child a psychological sense of security, precluding the advent of obsessive-compulsive symptoms. Controlling parents attach great importance to the compliance behavior of children. They take measures of punishment and arbitrary discipline to limit their autonomy, easily leading to children's anxiety, and making them pay too much attention to the details of life. Obsessive-compulsive behaviors are developed from long-term psychological contradictions. On one hand, parents should pay attention to the emotional communication with their children, hold realistic and reasonable expectations, give children positive evaluations, provide them with appropriate encouragement and rewards, in order to create a democratic, relaxed family environment. On the other hand, parents should also strive to prevent the occurrence of excessive emotions or emotional unbalance in the education process, such as avoid spoiling the children, making all the decision for the children, being too strict on boys, holding excessively high expectations; instead, parents should offer positive emotional care and attention.

College students' perfectionism positively predicts their obsessive-compulsive symptoms. The pursuit of perfection makes it easy for individuals to overestimate their own responsibility regarding negative events (Bouchard et al., 1999). Fear of taking responsibility causes fear and anxiety in doing anything wrong, which leads to the occurrence of obsessive-compulsive symptoms. Furthermore, seeking perfection is the predictive behavior for obsessive compulsive thinking and checking (Rice \& Pence, 2006); therefore, the higher the perfectionism drive, the more intransigent the obsessive-compulsive symptom. College students 
should pay attention to the cultivation of their own abilities, to understand that setting goals too high or too low is not conducive to individual learning motivation and good learning effect, and is not suitable for the individual's psychology development. Only realistic targets in actual situations give individuals strong motivation to strive and succeed. In real life, many college students' expectations and requirements are too high, so they are easily plagued by negative emotions. College students should learn to adjust their expectations and establish their own goals, take part in some mental health activities held by colleges and universities, pay attention to cultivate their abilities and read books conducive to mental health, find suitable methods to relieve stress, hold a positive attitude in confronting difficulties and challenges, as well as improve their social adaptation and resilience.

We found that parenting behavior of denial and dissatisfaction has indirect effects on college students' obsessive-compulsive symptoms through perfectionism. Some studies have found that parents' denial attitude easily makes their children feel distrust and pressure, resulting in excessive perfectionism (Rice et al., 2006), perfectionism is the risk factor of the onset of obsessive-compulsive symptoms. Xie (2005) pointed out that college students' perfectionism tendency and abnormal psychological symptoms are significantly related; the more they pursue perfection, the more easily for them to experience compulsion, depression and other psychological disorders. Therefore, parents' denial and dissatisfaction will affect the children's perfectionism and the occurrence of obsessive-compulsive symptoms. Parents should pay attention to the details of their parenting behavior, avoid the words and actions of discontent, and offer comments with encouragement and appreciation. Schools can also promote scientific and reasonable parenting education through text messages (cf. WeChat and network pages), while working together with parents to create a suitable living environment for preserving college students' mental health.

In this study, we verified the mediating effect of perfectionism in the parenting style on children's obsessive-compulsive symptoms, but in research methods, relying solely on the questionnaire survey method made it difficult to avoid the disadvantages, such as the difficulty to balance background variables when sampling. Due to resource constraint, the sample coming only from Suzhou, China, making generalization to the whole country questionable. Since three questionnaires represent a large total number of questions, it was easy to produce the fatigue effect which reduced its validity. Selecting college students as subjects has advantages in the sample selection and validity of the questionnaire survey. The results also have practical guiding significance, but the influence of parenting behavior on college students was weakened; even if the effect was significant, it was difficult to make substantive intervention according to their age. In the model construction, the pairwise variables were correlated, but the significance was low, so in the structural equation model, the total effect of the independent variables on the dependent variable was not high; thus, the explanatory power of the mediation model was limited. 
According to the research limitations, suggestions for future research on college students with the obsessive-compulsive symptoms include: in addition to questionnaires survey, other methods, such as interviews and experiments could be adopted. The subjects selected should try to balance the possible influencing factors, explore the influences of other independent variables on college students' obsessive-compulsive symptoms, especially the variables with immediate impacts on college students, thus making effective intervention. Further study concerning the influences of parental rearing patterns toward children and adolescents on their personality and obsessive-compulsive symptoms could be conducted. Moreover, longitudinal studies could be performed to explore the relationship among parental rearing patterns, personality traits of perfectionism, and obsessive-compulsive symptoms. For the verification of the mediating effect of perfectionism, future researchers can also improve the reliability and validity of the measurement tools, combined with various statistical methods to avoid the statistical deviation of employing a single method.

\section{Conclusion}

Existing research results predict the mediating role of perfectionism between the parenting patterns and the obsessive-compulsive symptoms. The results herein verify the hypothesis; the structural equation model reveals the relationships among the parenting behavior of college students, perfectionism and the obsessive-compulsive symptoms.

The results of the study provide specific insights and guidance for the mental health centers in colleges and universities, as well as for family education. In general, college educators should pay attention to the psychological adjustment of college students, and carry out the activities to relieve stress and improve the psychological status of college students. Schools should pay more attention to the adaptation problems of students in lower grades, and start fraternities, seminars and other activities to enable the students to quickly adapt to college life. They can also popularize scientific and reasonable education knowledge through text messages, WeChat, Internet homepage and other forms, and work together with parents to create suitable learning and living environment for college students' mental health.

\section{References}

Alonso, P., Menchón, J. M., Mataixcols, D., Pifarré, J., Urretavizcaya, M., Crespo, J. M. et al. (2004). Perceived Parental Rearing Style in Obsessive-Compulsive Disorder: Relation to Symptom Dimensions. Psychiatry Research, 127, 267-278. https://doi.org/10.1016/j.psychres.2001.12.002

Aycicegi, A., Harris, C. L., \& Dinn, W. M. (2002). Parenting Style and Obsessive-Compulsive Symptoms and Personality Traits in a Student Sample. Clinical Psychology \& Psychotherapy, 9, 406-417. https://doi.org/10.1002/cpp.338

Bandura, A., \& Kupers, C. J. (1964). Transmission of Patterns of Self-Reinforcement through Modeling. Journal of Abnormal Psychology, 69, 1-9. 
https://doi.org/10.1037/h0041187

Baron, R. M., \& Kenny, D. A. (1986). The Moderator-Mediator Variable Distinction in Social Psychological Research: Conceptual, Strategic, and Statistical Considerations. Journal of Personality and Social Psychology, 51, 1173-1182. https://doi.org/10.1037/0022-3514.51.6.1173

Barrett, P. M., Rapee, R. M., Dadds, M. M., \& Ryan, S. M. (1996). Family Enhancement of Cognitive Style in Anxious and Aggressive Children. Journal of Abnormal Child Psychology, 24, 187-203. https://doi.org/10.1007/BF01441484

Barrett, P., Shortt, A., \& Healy, L. (2002). Do Parent and Child Behaviours Differentiate Families Whose Children Have Obsessive-Compulsive Disorder from Other Clinic and Non-Clinic Families? Journal of Child Psychology and Psychiatry, 43, 597-607. https://doi.org/10.1111/1469-7610.00049

Bouchard, C., Rhéaume, J., \& Ladouceur, R. (1999). Responsibility and Perfectionism in Ocd: An Experimental Study. Behaviour Research \& Therapy, 37, 239-248. https://doi.org/10.1016/S0005-7967(98)00141-7

Bundros, J., Clifford, D., Silliman, K., \& Neyman, M. M. (2016). Prevalence of Orthorexia Nervosa among College Students Based on Bratman's Test and Associated Tendencies. Appetite, 101, 86-94. https://doi.org/10.1016/j.appet.2016.02.144

Chen, Y. J., Liu, D. Z., \& Zhu, J. R. (2013). Comparison of the Sex Roles Development of College Students between Taiwan and the Mainland. Journal of Higher Education, No. 6, 62-69.

Chen, Z. J., Wang, Y., \& Liao, Y. (2010). Study on Parental Rearing Style of Patients with Obsessive-Compulsive Disorder. Journal of Clinical Psychiatry, 20, 184-185.

Ehiobuche, I. (1988). Obsessive-Compulsive Neurosis in Relation to Parental Child-Rearing Patterns amongst the Greek, Italian, and Anglo-Australian Subjects. Acta Psychiatrica Scandinavica, 78, 115-120. https://doi.org/10.1111/j.1600-0447.1988.tb09009.x

Flett, G. L., \& Hewitt, P. L. (2002). Perfectionism: Theory, Research, and Treatment. American Journal of Psychiatry, 161, 1511-1511.

Frost, R. O., \& Marten, P. A. (1990). Perfectionism and Evaluative Threat. Cognitive Therapy \& Research, 14, 559-572. https://doi.org/10.1007/BF01173364

Gong, F., \& Lv, L.-H. (2012). The Comparison of Undergraduate Students' Learning Engagement between Research Universities in China and USA. Journal of Higher Education, 33, 90-100.

Hollender, M. H. (1978). Perfectionism, a Neglected Personality Trait. Journal of Clinical Psychiatry, 39, 384-394.

Huz, I., Nyer, M., Dickson, C., Farabaugh, A., Alpert, J., Fava, M. et al. (2016). Obsessive-Compulsive Symptoms as a Risk Factor for Suicidality in U.S. College Students. Journal of Adolescent Health Official Publication of the Society for Adolescent Medicine, 58, 481-484. https://doi.org/10.1016/j.jadohealth.2015.11.011

Jun, Z. (2007). Male and Female Sex Is Different. Public Health, No. 7, 84-85.

Kaner, A., Bulik, C. M., \& Sullivan, P. F. (1993). Abuse in Adult Relationships of Bulimic Women. Journal of Interpersonal Violence, 8, 52-63. https://doi.org/10.1177/088626093008001004

Kirk, R. E. (1996). Practical Significance: A Concept Whose Time Has Come. Educational \& Psychological Measurement, 56, 746-759. https://doi.org/10.1177/0013164496056005002

Klibert, J., Lamis, D. A., Collins, W., Smalley, K. B., Warren, J. C., Yancey, C. T. et al. (2014). Resilience Mediates the Relations between Perfectionism and College Student 
Distress. Journal of Counseling \& Development, 92, 75-82.

https://doi.org/10.1002/j.1556-6676.2014.00132.x

Li, N.-N., Jie, L. I., Zhou, X. N., Ma, J.-P., Sang, L. J., Chen, G. X. et al. (2011). Factors Affecting Resilience in Medical Students. Chinese Preventive Medicine, 12, 878-880.

Martinelli, M., Chasson, G. S., Wetterneck, C. T., Hart, J. M., \& Björgvinsson, T. (2014). Perfectionism Dimensions as Predictors of Symptom Dimensions of Obsessive-Compulsive Disorder. Bulletin of the Menninger Clinic, 78, 140-159. https://doi.org/10.1521/bumc.2014.78.2.140

Melli, G., Carraresi, C., \& Doron, G. (2015). The Role of Perfectionism in Relationship Obsessive-Compulsive Disorder (ROCD). Eabct Congress.

Mrdjenovich, A. J., \& Bischof, G. H. (2003). Obsessive-Compulsive Complaints and Academic Performance in College Students. College Student Journal, 37, 145-146.

Obsessive Compulsive Cognitions Working Group (1997). Cognitive Assessment of Obsessive-Compulsive Disorder. Behavior Research \& Therapy, 35, 667-681.

Rice, K. G., \& Pence Jr., S. L. (2006). Perfectionism and Obsessive-Compulsive Symptoms. Journal of Psychopathology and Behavioral Assessment, 28, 103-111. https://doi.org/10.1007/s10862-006-7488-4

Schaub, M. (2010). Parenting for Cognitive Development from 1950 to 2000 the Institutionalization of Mass Education and the Social Construction of Parenting in the United States. Sociology of Education, 83, 46-66. https://doi.org/10.1177/0038040709356566

Schweitzer, R. D., \& Hamilton, T. K. (2002). Perfectionism and Mental Health in Australian University Students: Is There a Relationship? Journal of College Student Development, 43, 684-695.

Sica, C., Caudek, C., Bottesi, G., De Fazio, E., Ghisi, M., Marchetti, I., \& Orsucci, A. (2013). Fathers' "Not Just Right Experiences" Predict Obsessive-Compulsive Symptoms in Their Sons: Family Study of a Non-Clinical Italian Sample. Journal of Obsessive-Compulsive and Related Disorders, 2, 263-272.

https://doi.org/10.1016/j.jocrd.2013.04.003

Storch, E. A., Geffken, G. R., Merlo, L. J., Jacob, M. L., Murphy, T. K., Goodman, W. K. et al. (2007). Family Accommodation in Pediatric Obsessive-Compulsive Disorder. Journal of Clinical Child and Adolescent Psychology, 36, 207-216. https://doi.org/10.1080/15374410701277929

Wu, H. D. (2006). Study on the Relationship between Obsessive-Compulsive Symptom and Psychological Defense Mechanism of College Students. Doctoral Dissertation, Hohhot: Inner Mongolia Normal University.

Xie, Y. L. (2005). Compilation of Self-Perfection Questionnaire for Undergradutes. Chinese Journal of Clinical Rehabilitation, 9, 102-105.

Yang, J. W., Cai, K. X., \& Fan, R. Q. (2009). The Characteristics of College Students' Psychological Stress and Coping Style. Chinese Journal of School Health, 30, 1129-1130.

Zhang, M., \& Chen, Y. H. (2013). Parenting Style and Procrastination: The Mediation Effects of Perfectionism. Studies of Psychology and Behavior, No. 2, 245-250.

Zhang, S. J. (1991). A Preliminary Study on the Symptomatology of Obsessive-Compulsive Disorder. Chinese Mental Health Journal, 2, 79-81. 


\section{Appendix}

Parenting Behavior Scale for College Students (PBSCS)

Completely
disagree Disagree General Agree $\begin{gathered}\text { Completely } \\ \text { agree }\end{gathered}$

1. I think my parents interfering me a lot

2. Most of my affairs are in the control of my parents

3. My parents are very strict with me

4. I am often punished by my parents

5. My parents don't respect my privacy

6. I can feel my parents' love for me

7. I think there is a warm, considerate and affectionate feeling with my parents

8. I can get my parents' understanding and comfort when I am in trouble

9. When I feel sad, I can get comfort from my parents

10. I find it hard to get close to my parents

11. Parents give me a lot of trust in many things

12. My parents allowed me to make some decisions independently

13. For my education, parents give priority to encouragement

14. I think my parents are very respectful of my point of view

15. My parents' punishment for me is fair and appropriate

16. My parents didn't allow me to do things that other children could do because they were afraid that I would have an accident.

17. In general, my parents obey me without question

18. In the eyes of my parents, I have no mistake

19. Parents always thought their unhappiness was caused by me

20. My parents often say to me like this, "is this the reward that we get for taking care of you all

$$
\text { day?" }
$$

21. My parents have a lot of dissatisfaction with me

22. My parents often criticize me in front of others and make me embarrassed

23. My parents seem to be indifferent to me

24. My parents don't care much about me

25. My relationship with my parents is quite estranged 
Perfectionism Questionnaire for College Students (PQCS)

\begin{tabular}{c} 
Completely Disagree General Agree $\begin{array}{c}\text { Completely } \\
\text { agree }\end{array}$ \\
\hline
\end{tabular}

1. I set a higher goal than most people

2. I expect to have a better performance than most people in my daily work

3. I want to be competent in everything I do.

4. I do everything and pursue perfection everywhere

5. I try to be a well-organized person and work is very organized

6. I think things should be taken back to the original place

7. I hope that things can be carried out and developed according to the original plan

$$
\text { 8. I'm a tidy man }
$$

9. If I fail at work or in school, it shows that I am no longer good

10. If I can't do well, I may lose respect.

11. I don't think it's a big deal to make a mistake occasionally

12. If I make mistakes when doing things or studying, I will feel totally defeated

13. I care very much about what other people say to me

14. I can't stand the neglect of others

15. I care about getting someone else's affirmation

16. I often hesitate about small things

17. It takes me a long time to do something good enough

18. Doing one thing will make a timely reflection on the individual parts of the process

19. Think twice about the decision to decide whether it is right or wrong

20. Most people say it's good, but I still feel that

$$
\text { I need to improve }
$$

21. Often feel guilty about my own mistakes or

$$
\text { omissions }
$$

22. For a long time, I have been thinking about what I regret and often reproach myself 23. My parents and friends want me to get

$$
\text { ahead }
$$

24. Only do something very well can not let my parents down

25. My parents want me to be the best in everything 
Obsessive-Compulsive Disorders Questionnaire for College Students (OCDQCS)

Never Occasionally Sometimes Often Always

1. When I speak, I always like to repeat the same words or sentences a few times

2. I feel that I can't explain things clearly, especially when it comes to me

3. When riding, it sometimes produces an impulse to hit someone or something

4. The idea of sex often appears in the mind

5. I don't want to throw away the old things

6. I returned many times to check doors, windows, drawers and so on to make sure they were really closed

7. Sometimes I start counting objects for no reason at all. Like the trees, the poles, the people passing me or the steps or anything

8. When I pack up at night, they must be put in place

9. I think what others have used or touched is harmful to myself

10. Often there's a indelicacy, filthy idea, and difficult to get rid of

11. Very concerned about the cleanliness and neatness of the workbook

12. Repeatedly check the turned off gas switch, faucet and light switch

13. There is a lot of doubt about what I do

14. The place where someone else is sitting is not clean and needs to be cleaned or wiped before sitting

15. The mind is often filled with fantasies of the opposite sex

16. Follow a strict routine when doing everyday things

17. More concerned about bacteria and diseases than ordinary people

18. In some cases, the fear of losing self-control makes an embarrassing thing

19. Even though I have done very carefully, I often feel that I am not good enough.

20. Everything has a fixed position

21. My room is stacked with a lot of empty, old, or actually not needed, because I think they may be used some day in the future

22. I feel that I can't help repeating certain Numbers.

23. There will be unwarranted impulses and ideas that want to hurt myself, others, or animals 


\section{Continued}

24. When a car comes rushing in, sometimes wants to bump into it

25. More than ordinary people use soap

26. There are unnecessary thoughts or words in the mind

\section{Have a poor memory}

28. Worry about my own dress and deportment

29. Feel difficult to complete the task

30. Work must be done slowly to ensure that it is done correctly

31. Things must be checked repeatedly

32. It is difficult to make a decision

$$
\begin{aligned}
& \text { 33. The brain is empty } \\
& \text { 34. I can't concentrate }
\end{aligned}
$$

35. I have to wash my hands, count or touch something again and again 